\title{
The Effect of Stimulus Bandwidth on Perception of Fricative /s/ among Individuals with Different Degrees of Sensorineural Hearing Loss
}

\author{
Neha Yadav \\ Department of Audiology and Speech Language Pathology, Bharat ENT Hospital, Bhiwani, India \\ Email: aslpnehayadav@gmail.com
}

S. B. Rathna Kumar

Centre for Applied Linguistics and Translation Studies, University of Hyderabad, Hyderabad, India Ali Yavar Jung National Institute for the Hearing Handicapped, Southern Regional Centre, Secunderabad, India Email: sarathna@yahoo.co.in

\author{
S. B. Annapurna \\ MERF Institute of Speech and Hearing, Madras ENT Research Foundation, Chennai, India \\ Email: annapurna.savalam@gmail.com
}

\author{
V. Josephine Vinila \\ Ali Yavar Jung National Institute for the Hearing Handicapped, Southern Regional Centre, Secunderabad, India \\ Email: josephinevinila@yahoo.co.in
}

\begin{abstract}
Most of the speech sounds that contribute to speech intelligibility are dominated by high-frequency components. The phoneme / $/$ / is the third or fourth most frequently occurring phoneme in the English language and second most frequently occurring consonantal phoneme in Hindi language. Given the importance of the phoneme $/ \mathrm{s} /$, it is ironic that, this sound contains the highest frequency acoustic elements of any speech sound in English and most of the non-English languages ranging from $4500 \mathrm{~Hz}$ to more than 8000 Hz. The most common type of hearing impairment affecting speech perception is high-frequency sensorineural loss (SN) and such individuals require good high frequency audibility in order to better perceive fricative cues, regardless of hearing status. While many studies appear to support the general notion that high-frequency amplification may not always be beneficial, the inter-subject variability in most studies precludes a clearly defined rule that would distinguish listeners who are likely to benefit from high-frequency amplification from those who are not. The current study is aimed to determine and compare the effective bandwidth required for the perception of fricative / $/$ / in individuals with normal hearing and hearing impairment as a function of degree of hearing loss. A total of 100 Hindi speaking subjects equally divided into four groups (Group I: Normal hearing, Group II: Moderate SN hearing loss, Group III: Moderately severe SN hearing loss, Group IV: Severe SN hearing loss) participated in the study. Nonsense syllables containing the phonemes /s/, /f/, /s / and /c/ in /i/ vowel context and low pass filtered at 1, 2, 3, 4, 5, 6, 7, 8 and $9 \mathrm{KHz}$ produced by a female talker were used as stimulus. The results revealed that there was a statistically significant effect $(p<0.05)$ of bandwidth for the perception /s/ between different groups at $1 \mathrm{KHz}, 2 \mathrm{KHz}, 3 \mathrm{KHz}, 4 \mathrm{KHz}, 5 \mathrm{KHz}, 6 \mathrm{KHz}, 7$ $\mathrm{KHz}$ and $8 \mathrm{KHz}$ and no significant effect $(\mathrm{p}>0.05)$ was seen at $9 \mathrm{KHz}$ between groups. In addition, individuals with normal hearing required lower bandwidth for accurate fricative perception and there was a statistically significant difference $(\mathbf{p}<\mathbf{0 . 0 5})$ in mean bandwidth between groups. Among the hearing impaired group, as the degree of hearing loss increased the subjects required higher bandwidth for accurate perception of fricative. This study has important implications in knowing the effective bandwidth required for the perception of high frequency speech sounds among individuals with hearing loss on individual basis which in turn helps in the selection of appropriate rehabilitative devices.
\end{abstract}

Index Terms - High Frequency Hearing Loss, fricative /s/, stimulus bandwidth, speech perception

\section{INTRODUCTION}

Speech perception is the process of transforming a continuously changing acoustical signal into discrete linguistic units (Rvachew \& Grawburg, 2006). The study of speech perception is concerned with the listener's ability to perceive the acoustic waveforms produced by a speaker as a string of meaningful words and ideas (Goldinger, Pisonic \& Logan, 1991). Hearing is a vital sense that is necessary for the development and maintenance of acoustic communication skills. To be able to hear and comprehend speech, good auditory integrity is required. Individuals with hearing loss are bound to have difficulty in perception of speech. Therefore, it is the essential duty of audiologists to identify, evaluate and 
rehabilitate aurally handicapped individuals. One of the common hearing impairment affecting speech perception is sensorineural hearing loss.

Sensorineural hearing loss occurs due to damage to the transduction mechanism of the inner ear and due to abnormality in the auditory nerve, which are responsible for sensing sounds of different pitches. A common complaint among individuals with sensorineural hearing loss (SNHL) is difficulty understanding speech, particularly under adverse listening conditions (Crandell, 1991). The extent and nature of the difficulty depends partly on the severity of the hearing loss. Individuals with mild or moderate loss can usually understand speech reasonably well when they are in quiet room with only one person talking. However, they have difficulty when more than one person is talking at a time, or when background noise or reverberations are present. Individuals with severe or profound loss usually have difficulty even when listening to a single talker in a quiet room and they generally have severe problems when background noise is present. Hence their ability to understand speech relies heavily on lip reading and use of context.

The most common type of hearing impairment affecting speech perception is high-frequency sensorineural loss and such individuals have some access to low-frequency sounds, with limited access to higher frequency sounds (Davis, 1995). These individuals often miss out on high-frequency components of speech, such as consonant sounds and can have difficulties understanding speech in background noise. Many sounds that contribute to speech intelligibility are dominated by high-frequency components. Furthermore, young children with hearing impairment who are learning a language for the first time benefit from being able to hear the high-frequency speech sounds that they are trying to produce (Stelmachowicz, Lewis, Choi \& Hoover, 2007).

In addition to these benefits for speech perception and production, the audibility of high-frequency sounds, provides other advantages (Simpson, Hersbach \& McDermott, 2005). For example, some valuable information about the source of sounds, such as birdsong and various important environmental noises are conveyed principally by high-frequency components. The subjective quality of these sounds tends to be judged as relatively poor if the high frequencies are too soft or inaudible (Moore \& Tan, 2003).

Acoustically, conversational speech has the most energy between approximately $500 \mathrm{~Hz}$ and $3000 \mathrm{~Hz}$. This mid frequency region is important for understanding speech, particularly speech that is meaningful such as words, sentences, or passages (Pavlovic, 1987; Studebaker, Pavlovic \& Sherbecoe, 1987 and Studebaker \& Sherbecoe, 2002). However, speech energy above $3000 \mathrm{~Hz}$ (high frequency region sounds) also offers listeners important linguistic information. High frequency speech information is extremely important for appreciation of music, detection of environmental sounds, and it serves several important linguistic functions in day to day communication (Kuk, Korhonen, Peeters, Keenan, Jessen \& Andersen, 2006). Elfenbein, Hardin-Jones \& Davis (1994) found that production and perception of fricatives may be difficult for listeners with sensorineural hearing loss.

Given the importance of the /s/ phoneme, this sound contains the highest frequency acoustic elements of any sound in the English and most of the non-English languages. Therefore, the perception of /s/ phoneme is the most challenging for the average hearing-impaired listener. It is the third or fourth most frequently occurring phoneme in the English language and serves multiple linguistic functions, including plurality, tense, and possession (Tobias, 1959; Denes, 1963 and Rudmin, 1983). Fricative /s/ is the second most frequently occurring phoneme among the overall used consonantal phonemes of Hindi (an Indo-Aryan) language (calculated from phonetically balanced words in Hindi (AIIMS, 1968 \& 1969).

An analysis of the acoustic spectrum of /s/ shows that it has most of its significant energy well above $4000 \mathrm{~Hz}$, ranging from $4500 \mathrm{~Hz}$ to more than $8000 \mathrm{~Hz}$ (Boothroyd, \& Medwetsky, 1992). This suggests that most people with a high-frequency hearing loss must depend upon the lower frequency elements of /s/ and other high-frequency voiceless consonants in order to barely perceive them. Hence listeners require good high frequency audibility in order to better perceive fricative cues, regardless of hearing status. Among both adults and children with hearing loss, /s/ is one of the most frequently misperceived phonemes (Owens, Benedict \& Schubert, 1972; Bilger \& Wang, 1976; Owens, 1978; Dubno \& Dirks, 1982 and Danhauer, Abdala, Johnson \& Asp, 1986). Boothroyd \& Medwetsky (1992) suggested that the current hearing aids may require a wider bandwidth (up to $10 \mathrm{KHz}$ ) to ensure the audibility of voiceless fricatives and high frequency linguistic information for female speakers.

As evidenced by many examples provided above, high frequency speech information is extremely important for speech comprehension, detection of environmental sounds, and safety. Unfortunately, this frequency region is difficult to amplify sufficiently using conventional hearing aids. Thus reduced audibility of the high frequency components of speech due to limited stimulus bandwidth of current hearing aids would be expected to impair self monitoring and thus may contribute to poorer production of fricatives and affricates.

The conventional hearing aid technology is limited in its ability to provide adequate gain for soft, high frequency speech sounds, particularly the fricative consonants. It is difficult to achieve sufficient gain in the frequency spectrum above $3000 \mathrm{~Hz}$ thus limiting the ability of the typical infant with hearing loss to hear high-frequency consonants, particularly the fricative sounds (Hayes \& Northern, 1996). If suitable gain is achieved in the high frequency region, acoustic feedback may result when the hearing aid is worn by the listener (Beamer, Grant \& Walden, 2000).

Apart from limited ability to provide sufficient high-frequency gain, conventional hearing aids provide too much gain at low frequencies (Bratt \& Sammeth, 1991) and too much low-to mid-frequency gain which may mask the important 
high-frequency speech information (i.e. upward spread of masking) potentially resulting in speech recognition deficits (Cook, Bacon \& Sammeth, 1997 and Gange, 1998).

Additionally, the output bandwidth of conventional hearing aids is not broad enough to make high-frequency sounds consistently audible due to the technical difficulty of combining high power and high bandwidth in the same transducer (Gange, 1998). These factors limit the audibility of important high-frequency speech sounds, especially for children with sloping and/or severe to profound hearing loss (Stelmachowicz, Pittman, Hoover, Lewis \& Moeller, 2004).

Studies suggested that listeners who are provided with audibility at frequencies where hearing levels are severe and/or sloping will not show speech recognition benefit due to the limited ability to use the amplified signal in that frequency region (Hogan \& Turner, 1998 and Ching, Dillon, Katsch \& Byrne, 2001). This lack of benefit of highfrequency amplification, when found, has been attributed by many researchers to the presence of non-functioning inner hair cells over a certain region of the cochlea- that is, dead regions (Baer, Moore \& Kluk, 2002; Moore, Glasberg \& Baer, 1997 and Vickers, Baer \& Moore, 2001).

On the other hand, other studies have reported that significant improvements in speech understanding, especially in noisy environments, occur when listeners with sloping sensorineural hearing loss are provided with high frequency amplification (Turner \& Henry, 2002). Additionally, listeners with suspected dead regions in the high-frequencies perform better on speech recognition tasks when broadband amplification is used (Mackersie, Crocker \& Davis, 2004), while listeners without dead regions are better able to make use of high-frequency cues (Moore, 2004). Individual performance in such studies indicated that listeners receive varying degrees of speech recognition benefit from amplified high-frequencies.

\section{NEED AND SigNIFICANCE OF THE STUDY}

The most challenging hearing loss configurations that audiologists face are high frequency sloping and/or severe to profound sensory neural hearing losses. Evidence has been mounting that the current conventional hearing aid technology may not provide enough audibility of the high frequency energy for individuals with sloping and/or severe to profound hearing loss (Glista, Scollie, Bagatto, Seewald \& Johnson, 2009). Also recent studies suggest that reduced audibility in high frequencies (because of limited bandwidth of hearing instruments) may play role in delayed phonological development often seen in children with hearing impairment and also it leads to poor perception of fricative sounds in adult hearing aid users.

While many studies appear to support the general notion that high-frequency amplification may not always be beneficial, the inter-subject variability in most studies precludes a clearly defined rule that would distinguish listeners who are likely to benefit from high-frequency amplification from those who are not. Hence there is a need to determine the effective range of bandwidth required for each hearing impaired individual for the perception of high frequency speech sounds.

If the effective bandwidth for accurate perception of fricatives is determined, it will be useful to choose suitable amplification strategy required for better perception of high frequency speech sounds. The knowledge of effective stimulus bandwidth for hearing impaired individuals will help in determining candidacy for frequency compression hearing aids and cochlear implants. Hence, the current study is aimed to determine and compare the effective bandwidth required for the perception of fricative /s/ in individuals with normal hearing and hearing impairment as a function of varying degrees of hearing loss.

\section{METHOD}

\section{A. Aim of the Study}

The current study was undertaken to contribute to the existing review of literature for identifying the benefits of bandwidth variation on perception of high frequency speech sounds. The present study focused on perception of /s/ in context of other high frequency nonsense syllables as a function of varying degrees of hearing loss in a population of acquired sensorineural hearing impairment. The bandwidth cut-off frequency and degree of hearing loss were considered on assessing the benefits of bandwidth modulation.

\section{B. Subjects}

A total of 100 Hindi speaking subjects (200 ears) with an age range of 18-40 years participated in the study. The mean age of the group of subjects was 31.5 years. These subjects were further equally divided into four groups depending on their hearing status.

1. Group I: Consisted of 25 individuals (13 male \& 12 female) with normal hearing sensitivity and had pure tone thresholds $\leq 15 \mathrm{~dB}$ HL in the octave frequencies from $0.25 \mathrm{KHz}$ to $8 \mathrm{KHz}$.

2. Group II: Consisted of 25 individuals (13 male \& 12 female) with bilateral moderate sensorineural hearing loss and had pure tone thresholds in the range of 41-55 dB HL in the octave frequencies from $0.25 \mathrm{KHz}$ to $8 \mathrm{KHz}$.

3. Group III: Consisted of 25 individuals (13 male \& 12 female) with bilateral moderately severe sensorineural hearing loss and had pure tone thresholds in the range of 56-70 dB HL in the octave frequencies from $0.25 \mathrm{KHz}$ to 8 $\mathrm{KHz}$. 
4. Group IV: Consisted of 25 individuals ( 13 male \& 12 female) with bilateral severe sensorineural hearing loss and had pure tone thresholds in the range of 71-90 dB HL in the octave frequencies from $0.25 \mathrm{KHz}$ to $8 \mathrm{KHz}$.

\section{Instrumentation}

All the testing was done using a calibrated dual channel clinical audiometer MAICO MA 53 in sound treated room under headphones (TDH 39) with ambient noise maintained at minimum level to minimize interference to the testing (ANSI, 1991). A calibrated Immitance audiometer (Madsen Zodiac 901) was used to rule out presence of middle ear pathology. A Dell Laptop (InspironN5010) with windows 7 was used to deliver the stimuli.

\section{Development of the Test Stimuli}

Test stimuli used were consonant - vowel (CV) nonsense syllables comprised of phonemes /s/, /f/, /s / and /c/ in /i/ vowel context produced by a female talker. The /i/ vowel was used to minimize the vocalic transition which might be used as a cue to distinguish the fricatives from one another. Although the primary interest of this study was the perception of /s/, it was necessary to provide subjects with alternative stimuli that would confuse the client and reduce practice and order-effect. Hence other phonemes /f/, /ș / and /c/ were used as alternatives.

\section{E. Recording of the Stimuli}

All the recording and generation of speech stimuli was done using high quality audio-editing software "PROTOOL" in a sound treated audio studio. Speech sample were recorded at a comfortable utterance level in a sound-attenuated room using a condenser microphone at a distance of $12 \mathrm{~cm}$ from mouth, with flat frequency response at $10 \mathrm{KHz}$. All the speech stimuli were recorded by a female talker. Speech samples were then amplified and filtered at $10 \mathrm{KHz}$, and digitized at a sampling rate of $20 \mathrm{KHz}$ and 12 bit quantization in "PROTOOL" audio editing software. $20 \mathrm{KHz}$ sampling rate is selected in the study because use of relatively high sampling rates can have undesirable side-effects. The digital signal processor inside any modern hearing instrument is programmed to modify the sound signals at a rate that is equal or proportional to the sampling rate and it is common for the sampling rate in hearing instruments to be approximately $20 \mathrm{KHz}$. This choice means that the upper limit of the bandwidth in terms of sound produced by the HI must be about $10 \mathrm{KHz}$. In some devices, the sampling rate may be as low as $16 \mathrm{KHz}$ resulting in an acoustic bandwidth of less than $8 \mathrm{KHz}$.

\section{F. Signal Processing}

Multiple repetitions of each sample were obtained and samples with little or no transition were selected as stimuli for the study. To determine the influence of bandwidth on perception of high frequency voiceless consonant $/ \mathrm{s} /$, each nonsense syllable (/si/, /fi/, /ș / and /ci/) was low pass filtered in a sixth order Butterworth filter with rejection rate of 50 $\mathrm{dB}$ octave at 9 frequencies ( $1 \mathrm{KHz}$ to $9 \mathrm{KHz}$ ) to form 36 stimuli (4x6) including 9 target stimuli (i.e. /s/ filtered at 1, 2, 3 , 4, 5, 6, 7, 8 and $9 \mathrm{KHz}$ ). These 36 nonsense syllables were randomly arranged in terms of order of stimulus into two separate lists to form two different stimuli sequence. List 1 stimulus sequence was used for right ear and List 2 stimulus sequence was used for left ear. This was done to avoid order and practice effect.

\section{G. Procedure}

Before the experimental task all the subjects were screened for hearing sensitivity using a calibrated clinical audiometer MAICO MA 53 with TDH 39 ear phones. After the necessary screening of the clients, the line out of the Dell Laptop (InspironN5010) was connected to the dual channel audiometer MA 53 through an RF jack. The developed test material was played through a CD player, which was routed through MAICO MA 53 Diagnostic Clinical Audiometer and delivered through the TDH 39 headphones. All the subjects were tested monaurally with two lists and each ear was tested with different random list. The stimulus was presented at $65 \mathrm{~dB}$ SPL.

The subjects were tested in a sound-treated audiometric room. Each subject was given following instructions in Telugu "You will listen to few sounds presented through headphones. Listen carefully and when you hear sound you have to repeat as you hear them". An open set response in the form of an oral response was obtained. If the subject felt tired during the test, a short break was given. The lowest bandwidth where the subjects could repeat the syllable /si/ was calculated for each subject (both ears) in each group. The group percentages correct responses for each bandwidth was also calculated for each group.

\section{H. Statistical Analysis}

The data obtained was subjected to statistical analysis using the SPSS version 17.0 software. Since 25 subjects (50 ears) in each group were involved in the study the values were calculated for 50 ears in each group. Mean and standard deviation values of stimulus bandwidth required for the perception of /s/ were calculated for each group (both ears) and the data was subjected to one way ANOVA with repeated measures in order to find out significant difference between groups. The group percentage correct responses at each bandwidth was measured for each group (both ears) and in order to find out the significant effect of bandwidth among the group, the data was further subjected to Pearson ChiSquare test. The results are discussed in the next chapter.

\section{RESULTS AND DISCUSSION}


The current study was conducted to determine the effective stimulus bandwidth required for accurate perception of fricative /s/ and to compare the stimulus bandwidth required for accurate perception of fricative /s/ in individuals with normal hearing and hearing impaired individuals with varying degrees of sensorineural hearing loss. The main objectives of the study were:

1. To determine and compare the effect of bandwidths (i.e. $1 \mathrm{KHz}, 2 \mathrm{KHz}, 3 \mathrm{KHz}, 4 \mathrm{KHz}, 5 \mathrm{KHz}, 6 \mathrm{KHz}, 7 \mathrm{KHz}, 8$ $\mathrm{KHz}, 9 \mathrm{KHz})$ on group performance scores (\%) between different groups.

2. To determine and compare the mean bandwidth required for the perception of fricative /s/ between different groups

A. The Effect of Stimulus Bandwidth on Group Performance Scores (\%) for the Perception of Fricative /s/ between Different Groups

TABLE 1

GROUP PERFORMANCE SCORES (\%) BETWEEN DIFFERENT GROUPS ACROSS VARIOUS BANDWIDTHS

\begin{tabular}{|c|c|c|c|c|}
\hline \multirow{2}{*}{ Frequency } & \multicolumn{4}{|c|}{ Group Performance Correct Responses (\%) } \\
\hline & Group I & Group II & Group III & Group IV \\
\hline $1 \mathrm{KHz}$ & 0 & 0 & 0 & 0 \\
\hline $2 \mathrm{KHz}$ & 6 & 0 & 0 & 0 \\
\hline $3 \mathrm{KHz}$ & 42 & 0 & 0 & 0 \\
\hline $4 \mathrm{KHz}$ & 76 & 28 & 0 & 0 \\
\hline $5 \mathrm{KHz}$ & 96 & 72 & 30 & 0 \\
\hline $6 \mathrm{KHz}$ & 100 & 86 & 62 & 0 \\
\hline $7 \mathrm{KHz}$ & 100 & 96 & 88 & 2 \\
\hline $8 \mathrm{KHz}$ & 100 & 96 & 96 & 26 \\
\hline $9 \mathrm{KHz}$ & 100 & 100 & 100 & 98 \\
\hline
\end{tabular}

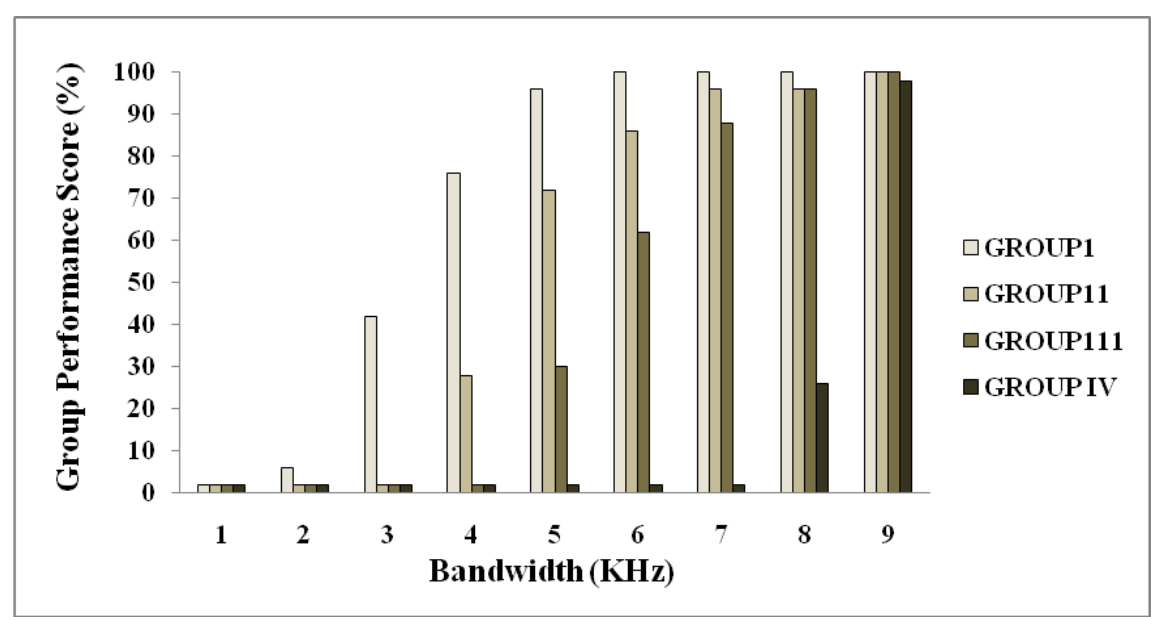

Figure 1: Comparison of group performance scores (\%) across various bandwidths

Individuals with normal hearing (Group I) obtained group mean percentage score of $0 \%, 6 \%, 42 \%, 76 \%$ \& $96 \%$ for 1 $\mathrm{KHz}, 2 \mathrm{KHz}, 3 \mathrm{KHz}, 4 \mathrm{KHz}, \& 5 \mathrm{KHz}$ respectively and a score of $100 \%$ at $6 \mathrm{KHz}, 7 \mathrm{KHz}, 8 \mathrm{KHz}$ and $9 \mathrm{KHz}$. Individuals with moderate hearing loss (Group II) obtained mean percentage score of $0 \%, 0 \%, 0 \%, 28 \%, 72 \% \& 86 \%$ at $1 \mathrm{KHz}, 2 \mathrm{KHz}, 3 \mathrm{KHz}, 4 \mathrm{KHz}, 5 \mathrm{KHz} \& 6 \mathrm{KHz}$ respectively and a score of $96 \%$ at $7 \mathrm{KHz} \& 8 \mathrm{KHz}$ and could achieve $100 \%$ score at $9 \mathrm{KHz}$. Individuals with moderately severe hearing loss (Group III) obtained mean percentage score of $0 \%, 0 \%, 0 \%, 0 \%, 30 \%, 62 \%, 88 \%, 96 \%$ \& $100 \%$ at $1 \mathrm{KHz}, 2 \mathrm{KHz}, 3 \mathrm{KHz}, 4 \mathrm{KHz}, 5 \mathrm{KHz}, 6 \mathrm{KHz}, 7 \mathrm{KHz}, 8 \mathrm{KHz}$ and 9 $\mathrm{KHz}$ respectively. Individuals with severe hearing loss (Group IV) obtained mean percentage score of $0 \%$, at $1 \mathrm{KHz}, 2$ $\mathrm{KHz}, 3 \mathrm{KHz}, 4 \mathrm{KHz}, 5 \mathrm{KHz} \& 6 \mathrm{KHz}$ and a score of $2 \%, 26 \%$ \& $98 \%$ at $7 \mathrm{KHz}, 8 \mathrm{KHz}$ and $9 \mathrm{KHz}$ respectively.

Thus the results revealed that individuals with normal hearing (Group I) could achieve a maximum group performance score of $100 \%$ at $6 \mathrm{KHz}$ Bandwidth whereas individuals with moderate (Group II) and moderately severe hearing loss (Group III) achieved a maximum score of $100 \%$ at $9 \mathrm{KHz}$ and individual with severe hearing loss (Group IV) could not achieve a score of $100 \%$ even at $9 \mathrm{KHz}$. They obtained a maximum score of $98 \%$ responses at $9 \mathrm{KHz}$ bandwidth.

Group I reached $80 \%$ group performance correct score at approximately $4.2 \mathrm{KHz}$ as compared to Group II, Group III and Group IV who reached $80 \%$ scores at $5.5 \mathrm{KHz}, 6.6 \mathrm{KHz}$ and $8.8 \mathrm{KHz}$ respectively. Hence it can be inferred that hearing impaired individuals require higher bandwidths for better performance on perception of /s/ as compared to normal subjects. 
Among the hearing impaired individuals, the group performance scores were better in group I as compared to group II and group III at $4 \mathrm{KHz}, 5 \mathrm{KHz}, 6 \mathrm{KHz}$ and $7 \mathrm{KHz}$. Group II and Group III showed similar performance at $8 \mathrm{KHz}$ and $9 \mathrm{KHz}$, whereas group IV performed poorly at all bandwidths.

The data was further subjected to Pearson Chi-square test of independence in order to find out significant effect of bandwidth for the perception of fricative /s/ between different groups. The results revealed that there was a statistically significant effect $(\mathrm{p}<0.05)$ of bandwidth for the perception /s/ between different groups at $1 \mathrm{KHz}, 2 \mathrm{KHz}, 3 \mathrm{KHz}, 4 \mathrm{KHz}$ $5 \mathrm{KHz}, 6 \mathrm{KHz}, 7 \mathrm{KHz}$ and $8 \mathrm{KHz}$ and no significant effect $(\mathrm{p}>0.05)$ was seen at $9 \mathrm{KHz}$ between groups. Hence, it can be inferred that the group performance was not similar up to $8 \mathrm{KHz}$ bandwidth, whereas at $9 \mathrm{KHz}$ the group performance was similar in all the groups.

\section{B. Comparison of Mean Bandwidth Required for the Perception of Fricative /s/ in Individuals between Groups}

TABLE 2

MEAN BANDWIDTH REQUIRED FOR THE PERCEPTION OF/S/ IN DIFFERENT GROUPS

\begin{tabular}{|c|c|c|c|c|}
\hline \multirow{2}{*}{ Group } & \multirow{2}{*}{$\mathbf{N}$ (Ears) } & \multicolumn{2}{|c|}{ Bandwidth (KHz) } & \multirow{2}{*}{$\begin{array}{l}\text { Significance } \\
\text { p-value }\end{array}$} \\
\hline & & Mean & SD & \\
\hline I & 50 & 3.78 & 0.95 & \multirow{5}{*}{$\begin{array}{l}0.000^{*} \\
(\mathrm{P}<0.05)\end{array}$} \\
\hline II & 50 & 5.22 & 1.20 & \\
\hline III & 50 & 6.26 & 1.08 & \\
\hline IV & 50 & 8.72 & 0.49 & \\
\hline Total & 200 & 6.00 & 2.04 & \\
\hline
\end{tabular}

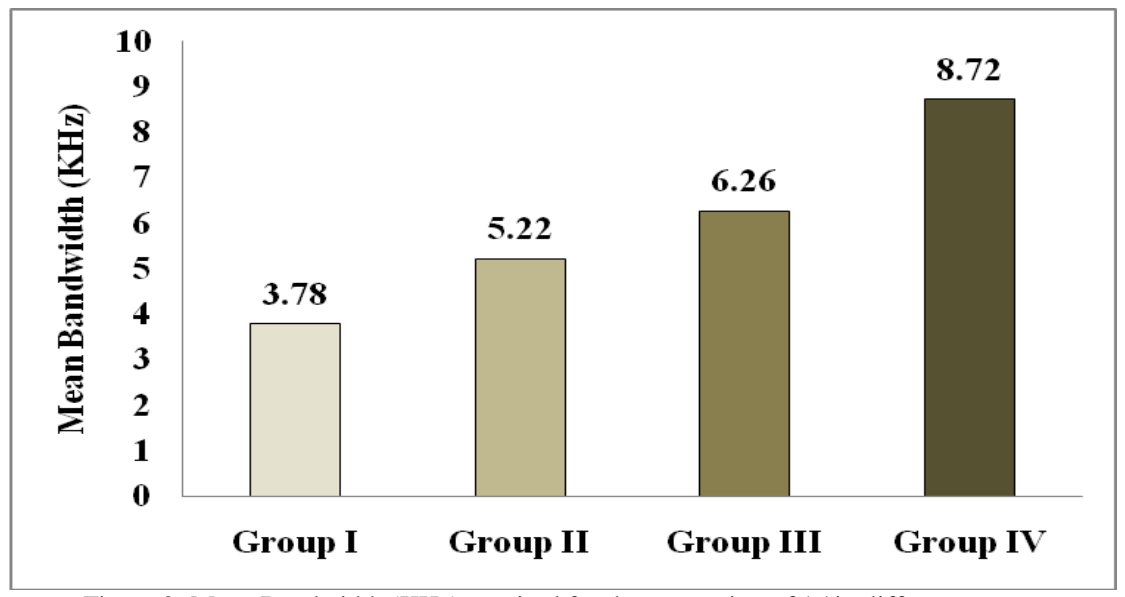

Figure 2: Mean Bandwidth (KHz) required for the perception of /s/ in different groups

The subjects obtained a mean bandwidth of $3.78 \mathrm{KHz}, 5.22 \mathrm{KHz}, 6.26 \mathrm{KHz}$ and $8.72 \mathrm{KHz}$ for the perception of /s/ in group I, Group II, Group III and Group IV respectively. In order to find out the significant mean difference in bandwidth to perceive fricative /s/ among groups, the data was subjected to one way ANOVA with repeated measures and the results showed that there was significant difference $(\mathrm{p}<0.05)$ in mean scores between groups and within groups.

Hence, the data was subjected to LSD Post Hoc test in order to find out significant difference between groups (i.e. Group I vs. Group II, Group I vs. Group III, Group I vs. Group IV, Group II vs. Group III, Group II vs. Group IV and Group III vs. Group IV). The results revealed that there was a statistically significant difference $(\mathrm{p}<0.05)$ in mean bandwidth between groups.

Individuals with normal hearing (Group I) perceived /s/ at a lower bandwidth $(3.78 \mathrm{KHz})$ as compared to the subjects in the hearing impaired groups. Among the hearing impaired groups, moderate hearing loss group perceived /s/ at lower bandwidth $(5.22 \mathrm{KHz})$ followed by moderately severe hearing loss group $(6.26 \mathrm{KHz})$ and severe hearing loss group $(8.72 \mathrm{KHz})$. Hence it can be inferred that hearing impaired individuals require higher bandwidths for the perception of /s/ as compared to normal subjects.

These findings are in accordance with the findings of Stelmachowicz, Pittman, Hoover \& Lewis (2001), who reported that listeners with moderate to moderately severe sensorineural hearing impairment needed an audible bandwidth of $4.2 \mathrm{KHz}$ to $6.9 \mathrm{KHz}$ for male speech, 6.3 to $8.8 \mathrm{KHz}$ for female speech, and $9 \mathrm{KHz}$ for child speech in order to understand fricatives especially /s/.

Among the hearing impaired individuals, the required bandwidth for the perception of /s/ increased, as the degree of hearing loss increased is an interesting finding of the study. These findings are in accordance with the findings of Ricketts, Dittberner \& Johnson (2008), who studied if preference for bandwidth extension in hearing aid processed sounds was related to the magnitude of hearing loss in individual listeners. They took 10 participants with normal hearing and 20 with mild to moderate hearing loss and processed signals using hearing aid style compression algorithms 
and filtered using two cut-off frequencies, $5.5 \mathrm{KHz}$ and $9 \mathrm{KHz}$, which were selected to represent bandwidths that are achievable in modern hearing aids. In conclusion, consistent preference for wider bandwidth is present in some listeners with mild- to- moderate hearing loss.

Hence, the hypothesis stating that there will not be any significant difference in mean bandwidth required for the perception of fricative /s/ in different groups is rejected (i.e. Group I vs. Group II, Group I vs. Group III, Group I vs. Group IV, Group II vs. Group III, Group II vs. Group IV and Group III vs. Group IV).

Although there was a significant effect of bandwidth on group performance, the subjects with moderate and moderately severe hearing loss could reach $100 \%$ at higher bandwidths. The performance of other groups improved as bandwidth increased but it was not seen in individuals with severe hearing loss despite providing the widest bandwidth (9 KHz). This could be explained in accordance with the results reported by Skinner (1980), Murray \& Byrne (1986), Rankovic (1998), Hogan \& Turner (1998) and Turner \& Cummings (1999). They reported that systematic increase in high-frequency gain may not improve, and in some cases may degrade, speech recognition for listeners with greater degrees of hearing loss. If amplifying speech to audible levels in the high frequencies does not improve speech recognition, then attempts to provide gain may not be necessary or desirable in certain cases.

Hogan \& Turner (1998) also investigated the effects of stimulus bandwidth on phoneme recognition in listeners with high frequency hearing losses. They reported benefit obtained by providing additional high-frequency audibility was negligible or negative when the degree of loss at and above $4 \mathrm{KHz}$ exceeded $55 \mathrm{~dB} \mathrm{HL}$. In some cases, performance decreased with increases in high-frequency audibility. Although above studies justify poor performance of severe hearing loss individuals at $9 \mathrm{KHz}$, this study findings disagree with the results of Hornsby \& Ricketts (2006), who reported improved speech recognition with increasing bandwidth in listeners with high-frequency hearing thresholds as poor as $85 \mathrm{~dB}$ HL. They reported small incremental improvements in speech recognition performance as the audible high-frequency energy was extended from $3.2 \mathrm{KHz}$ up to approximately $7 \mathrm{KHz}$.

\section{SUMMARY AND CONCLUSION}

The most challenging hearing loss configurations that audiologists face are high frequency sloping and/or severe to profound sensory neural hearing loss. Evidence has been mounting that the current conventional hearing aid technology may not provide enough audibility of the high frequency energy for such individuals. While many studies appear to support the general notion that high-frequency amplification may not always be beneficial, the inter subject variability in most studies precludes a clearly defined rule that would distinguish listeners who are likely to benefit from highfrequency amplification from those who are not. Hence there is a need to determine the effective range of bandwidth required for each hearing impaired individual for the perception of high frequency speech sounds. If the effective bandwidth for accurate perception of fricatives is determined, it will be useful to choose suitable amplification strategy required for better perception of high frequency speech sounds. The current study revealed that hearing impaired subjects required greater bandwidth for the perception of fricatives as compared to normal subjects. Among the hearing impaired individuals as the degree of hearing loss increased they required broader bandwidth for accurate perception of fricatives. This study has important implications in knowing the effective bandwidth required for the perception of high frequency speech sounds among individuals with hearing loss on individual basis which in turn helps in the selection of appropriate rehabilitative devices such as conventional hearing aids, cochlear implants, and frequency compression devices.

\section{REFERENCES}

[1] American National Standards Institute. (1991): American National Standard Criteria for Permissible Ambient Noise During Audiometric Testing, ANSI S3.1-1991. American National Standards Institute, New York.

[2] AIIMS. (1968, 1969): Phonetically Balanced Word Lists in Hindi: In Kacker, S. K., \& Basavaraj, V. Indian Speech, Language and Hearing Test-the ISHA Battery-1990. Mysore, ISHA.

[3] Baer, T., Moore, B. C. J. \& Kluk, K. (2002). Effects of low pass filtering on the intelligibility of speech in noise for people with and without dead regions at high frequencies. Journal of the Acoustical Society of America 112, 1133-1144.

[4] Beamer, S. L., Grant, K. W. \& Walden, B. E. (2000). Hearing aid benefit in patients with high-frequency loss. Journal of the American Academy of Audiology 11, 429-437.

[5] Bilger, R. C. \& Wang, M. D. (1976). Consonant confusions in patients with sensorineural hearing loss. Journal of Speech and Hearing Research 19, 718-748.

[6] Boothroyd, A. \& Medwetsky, M. S. (1992). Spectral distribution of /s/ and the frequency response of hearing aids. Ear and Hearing 13 (3), 150-157.

[7] Bratt, G. W. \& Sammeth, C. A. (1991). In M.C. Roup, \& M. C. Noe (2009), Hearing aid outcomes for listeners with high frequency hearing loss. American Journal of Audiology 18, 45-52.

[8] Ching, T. Y. C., Dillon, H., Katsch, R. \& Byrne, D. (2001). Maximizing effective audibility in hearing aid fitting. Ear \& Hearing 22(3), 212-224.

[9] Cook, J. A., Bacon, S. P. \& Sammeth, C. A. (1997). Effect of low-frequency gain reduction on speech recognition and its relation to upward spread of masking. Journal of Speech and Hearing Research 40, 410-422.

[10] Crandell, C.C. (1991). Individual differences in speech recognition ability: Implications for hearing aid selection. Ear \& Hearing 12, 100-108. 
[11] Davis, A. (1995). Hearing in adults. London: Whurr publications.

[12] Danhauer, J. L., Abdala, C., Johnson, C. \& Asp, C. (1986). Perceptual features from normal-hearing and hearing-impaired children's errors on the NST. Ear and Hearing 7, 318-322.

[13] Denes, P. B. (1963). On the statistics of spoken English. Journal of Acoustical Society of America 35: 892-904.

[14] Dubno, J. R. \& Dirks, D. D. (1982). Evaluation of hearing-impaired listeners using a nonsense-syllable test. Journal of Speech, Language, and Hearing Research 25, 135-141.

[15] Elfenbein, J. L., Hardin-Jones, M. A. \& Davis, J. M. (1994). Oral communication skills of children who are hard of hearing. Journal of Speech and Hearing Research 37, 216-226.

[16] Gange, J. P. (1998). Excess masking among listeners with a sensorineural hearing loss. Journal of the Acoustical Society of America 83, 2311-2321.

[17] Glista, D., Scollie, S., Bagatto, M., Seewald, R. \& Johnson, A. (2009). Evaluation of nonlinear frequency compression: Clinical outcomes. International Journal of Audiology 48(9), 632-44.

[18] Goldinger, D. D., Pisonic, D. B. \& Logan, J. S. (1991). On the nature of talker variability effect on recall of spoken word list. Journal of Experimental Psychology: Learning, Memory \& Cognition 17, 152-162.

[19] Hayes, D. \& Northern, J. L. (1996). Infants and Hearing. London, Singular Publication Group.

[20] Hogan, C. A. \& Turner, C. W. (1998). High-frequency audibility: benefits for hearing impaired listeners. Journal of the Acoustical Society of America 104, 432-441.

[21] Hornsby, B. W. \& Ricketts, T. A. (2006). The effects of hearing loss on the contribution of high-and low-frequency speech information to speech understanding in sloping hearing loss. Journal of the Acoustical Society of America 119, 1752-1763.

[22] Kuk, F., Korhonen, P., Peeters, H., Keenan, D., Jessen, A. \& Andersen, H. (2006). Linear frequency transposition: Extending the audibility of high frequency information. The Hearing Review 12(10), 42-48.

[23] Mackersie, C. L., Crocker, T. L. \& Davis, R. (2004). Limiting high-frequency hearing aid gain in listeners with and without suspected cochlear dead regions. Journal of the American Academy of Audiology 15, 498-507.

[24] Moore, B. C. J., Glasberg, B. R. \& Baer, T. (1997): A model for the prediction of thresholds, loudness and partial loudness. Journal of Audiological Engineering Society 45, 224-240.

[25] Moore, B. C. \& Tan, C. T. (2003): Perceived naturalness of spectrally distorted speech and music. Journal of Acoustical Society of America 114, 408-419.

[26] Moore, B. C. J. (2004). Dead regions in the cochlea: Conceptual foundations, diagnosis, and clinical applications. Ear and Hearing 25(2), 98-116.

[27] Murray, N. \& Byrne, D. (1986). Performance of hearing impaired and normal hearing listeners with various high frequencies cut-offs in hearing aids. Australian Journal of Audiology 8, 21-28.

[28] Owens, E., Benedict, M. \& Schubert, E. D. (1972). Consonant phonemic errors associated with pure-tone configurations and certain kinds of hearing impairment. Journal of Speech and Hearing Research 15, 308-322.

[29] Owens, E. (1978). Consonant errors and remediation in sensorineural hearing loss. Journal of Speech and Hearing Research 43 , 331-347.

[30] Pavlovic, C. V. (1987). Derivation of primary parameters and procedures for use in speech intelligibility predictions. Journal of the Acoustical Society of America 82, 413-422.

[31] Plyler, P. N. \& Fleck, E. L. (2006). The effects of high-frequency amplification on the objective and subjective performance of hearing instrument users with varying degrees of high-frequency hearing loss. Journal of Speech, Language and Hearing Research 49(3), 616-627.

[32] Rankovic, C. M. (1998). Factors governing speech reception benefits of adaptive linear filtering for listeners with sensorineural hearing loss. Journal of the Acoustical Society of America 103, 1043-1057.

[33] Ricketts, T. A., Dittberner, A. B. \& Johnson, E. E. (2008). High frequency amplification and sound quality in listeners with normal through moderate hearing loss. Journal of Speech and Hearing Research 51, 160-172.

[34] Rudmin, F. (1983). The why and how of hearing /s/. The Volta Review 85, 263-269.

[35] Rvachew, S. \& Grawburg, M. (2006). Correlates of phonological awareness in preschoolers with speech sound disorders. Journal of speech language and hearing research 49(1), 74-87.

[36] Simpson, A., Hersbach, A. A. \& McDermott, H. J. (2005). Improvements in speech perception with an experimental nonlinear frequency compression hearing device. International Journal of Audiology 44(5), 281- 292.

[37] Skinner, M. W. (1980). Speech intelligibility in noise-induced hearing loss: Effects of high-frequency compensation. Journal of the Acoustical Society of America 67, 306-317.

[38] Stelmachowicz, P. G., Pittman, A. L., Hoover, B. M. \& Lewis, D. E. (2001). Effect of stimulus bandwidth on the perception of /s/ in normal- and hearing-impaired children and adults. Journal of the Acoustical Society of America 110, 2183-2190.

[39] Stelmachowicz P. G., Pittman A. L., Hoover B. M., Lewis D. E. \& Moeller, M. P. (2004). The importance of high-frequency audibility in the speech and language development of children with hearing loss. Archives of Otolaryngology Head and Neck Surgery 130(5), 556-562.

[40] Stelmachowicz, P. G., Lewis, D., Choi, S. \& Hoover, B. (2007). Effect of stimulus bandwidth on auditory skills in normal hearing and hearing-impaired children. Ear \& Hearing 28, 483-494.

[41] Studebaker, G. A. \& Sherbecoe, R. L. (2002). Intensity-importance functions for band-limited monosyllabic words. Journal of the Acoustical Society of America 111, 1422-1436.

[42] Studebaker, G. A., Pavlovic, C. V. \& Sherbecoe, R. L. (1987). A frequency importance functions for continuous discourse. Journal of the Acoustical Society of America 81, 1130-1138.

[43] Tobias, J. V. (1959). Relative occurrence of phonemes in American English, Journal of the Acoustical Society of America 31, 6-31

[44] Turner, C. W. \& Cummings, K. (1999). Speech audibility for listeners with high-frequency hearing loss. Journal of the American Academy of Audiology 8, 47-56. 
[45] Turner, C. W. \& Henry, B. (2002). Benefits of amplification for speech recognition in background noise. Journal of the Acoustical Society of America 112, 1675-1680.

[46] Vickers, D. A., Baer, T. \& Moore, B. C. J. (2001). Effects of low-pass filtering on speech intelligibility for listeners with dead regions at high frequencies. British Journal of Audiology 35, 148-149.

Neha Yadav was born in Bhiwani, Haryana, India. Ms. Yadav has completed M. Sc (Audiology \& Speech Language Pathology) from Ali Yavar Jung National Institute for the Handicapped, Southern Regional Centre, Secunderabad, India in 2011. She received B Sc (Audiology \& Speech Language Pathology) from Sweekaar Degree and P.G College for Hearing Language and Speech, Secunderabad, India in 2009. She is currently working as Audiologist \& Speech Language Pathology at Bharat ENT Hospital, Bhiwani, Haryana, India.

S. B. Rathna Kumar was born in Guntur, Andhra Pradesh, India. Mr. Kumar received M. Sc (Speech \& Hearing) degree from All India Institute of Speech and Hearing, Mysore, India in 1998 and B. Sc (Hearing, Language \& Speech) from Ali Yavar Jung National Institute for the Hearing Handicapped, Secunderabad, India in 1996. He is currently working as Lecturer (Speech \& Hearing) at Ali Yavar Jung National Institute for the Hearing Handicapped, Secunderabad, India and pursuing Doctoral Studies in the area of Auditory Phonetics at Centre for Applied Linguistics \& Translation Studies, University of Hyderabad, India. He has published research articles in Indian Journal of otolaryngology and Head Neck Surgery, Journal of Linguistic Society of India and Language in India journals.

S. B. Annapurna was born in Guntur, Andhra Pradesh, India. Ms. Annapurna received M. Sc (Speech Language Pathology) degree from All India Institute of Speech and Hearing, Mysore, India in 2009 and B. Sc (Audiology \& Speech Language Pathology) from Ali Yavar Jung National Institute for the Hearing Handicapped, Secunderabad, India in 2007. She is currently working as a Senior Lecturer in the Department of Speech Language Pathology at MERF Institute of Speech and Hearing, Chennai, India and pursuing $\mathrm{PhD}$ in the field of Speech and Hearing at MS University, India. Her research interests focus on Speech \& Language Processing \& perception, childhood language disorders and cognitive impairments in adults.

V. Josephine Vinila was born in Secunderabad, Andhra Pradesh, India. Ms. Vinila received M. Sc (Audiology \& Speech Language Pathology) degree from Manipal Academy of Higher Education Institute of Speech and Hearing, Manipal, India in 2005 and B. Sc (Hearing, Language \& Speech) degree from Ali Yavar Jung National Institute for the Hearing Handicapped, Secunderabad, India in 2003. She is currently working as Audiologist \& Speech Language Pathologist at Ali Yavar Jung National Institute for the Hearing Handicapped, Secunderabad, India. 